\title{
Instructors' Perspectives on Learning Technologies in the Multidisciplinary Faculty of Land and Food Systems at the University of British Columbia, Canada
}

\author{
Julie E. Wilson, Junsong Zhang, Cyprien Lomas, Les M. Lavkulich, and Rickey Y. Yada
}

\begin{abstract}
The advent and rapid development of emerging technologies for teaching and learning present unprecedented opportunity for applications to higher education. Challenges arise to develop instructors' competencies and pedagogical use of learning technology to improve teaching and learning outcomes. To understand faculty members' perceptions of learning technologies and their current practices at the Faculty of Land and Food Systems, an investigation was carried out through semi-structured interviews $(n=23)$. Instructors were aware of existing and emerging technologies but face several challenges, including: whether emerging technologies augment teaching practices to achieve the desired learning objectives, the time needed to learn, adopt and adapt the techniques, establishing priorities in an already demanding schedule, and the limitations of technical and physical resources to allow effective use of the technology. Although instructors were willing to adopt the technologies, the type of training or assistance desired was inconsistent or not clearly articulated in interviews. Participants were positive about opportunities to communicate and share experiences with fellow instructors, but that emerging technologies require training. This training should be recognized as professional development considered in employee reviews and evaluations, and incentivized by incorporating it into career enhancement programs.
\end{abstract}

Index Terms-Higher education, instructor, interview, learning technology.

\section{INTRODUCTION}

Although higher education is evolving at a rapid rate as digital and emerging technologies are becoming a natural extension of our daily lives, the effective application of these technologies raise challenges for both institutions and instructors. Reference [1] advances a theory of "pull-push" to distinguish between education systems of the 20th and $21 \mathrm{st}$ centuries. 20th century education was largely characterized by how much information could be "pushed" to students, predominantly through lectures, note-taking and memorization. This passive learning trend was an artifact of the fact that very few education resources existed outside of the classroom. In the 21 st century, students' synthesis of

Manuscript received September 19, 2016; revised December 5, 2016. This study was approved by the UBC Behavioural Research Ethics Board, Approval number: H15-00269.

J. E. Wilson, C. Lomas, L. M. Lavkulich, and R. Y. Yada are with the Faculty of Land and Food Systems at the University of British Columbia, Vancouver, BC V6T 1 Z4 Canada (e-mail: julie.wilson@ubc.ca, cyprien.lomas@ubc.ca,1ml@mail.ubc.ca,r.yada@ubc.ca).

J. Zhang was with the Faculty of Education at the University of British Columbia. He is now with the Insurance Corporation of British Columbia (e-mail: zhangjunso77@gmail.com). information is "pulled" from an inundation of online resources and social networks, which is redefining educational practices [2]. The Flexible Learning Initiative (FLI) [3], adopted at UBC in 2013 is such an example, aiming to raise awareness amongst faculty of the benefits of blended learning (a mix of online and face-to-face), and other "flexible" options employing emerging technologies, to provide choices to learners and appeal to their different preferences [4], [5].

While emerging technologies provide more opportunities for a greater variety of course delivery formats, they can also be limiting for practitioners who have minimal technical experience. This becomes a challenge for leadership in higher education institutions, who are tasked with developing and overseeing strategies for uptake of innovative educational practices amongst faculty members. Although there are several studies on the opportunities offered by adoption of new and emerging technologies in higher education [5]-[7], as well as reports on the efficacy of these technologies in enhancing student learning [8]-[10], there are few studies on the challenges and possible barriers perceived by instructors for the adoption of these innovations. This study is viewed through the lens of Rogers' Diffusion of Innovation theory [11] to understand how innovations diffuse into social systems, and how this can be managed to ensure quick uptake in higher education.

The question raised here was how the FLI, and a move towards greater use of emerging technologies for courses, is being received by instructors in the Faculty of Land and Food Systems (LFS), a small $(<50$ full-time faculty), multidisciplinary faculty at the University of British Columbia, Vancouver, Canada. Educational practices are constantly developing and evolving in LFS. Instructors "link" to the FLI through the Centre for Teaching and Learning Technology (CTLT), which provides centralized services and support for instructors across the university, and a complementary Faculty unit, the Learning Centre (LC) [12], which promotes excellence in teaching and learning through various services to instructors and students. However, there is very little documented record of the use of emerging technologies to facilitate innovative educational practices.

The purpose of this study was to assess the development and diffusion of innovative educational practices in LFS. This study contributes to the university leadership's goals and strategies for continued optimization of teaching and learning practices, and use of emerging technologies in higher education. Specific objectives were to assess instructors' views and opinions on the following:

- What tools/technologies are currently used to support their 
teaching practices,

- Their perceived challenges in adopting the emerging technologies,

- What their instructional support needs are, and are they being met, and

- How they self-identify as an adopter of innovative educational practices with emerging technologies.

\section{METHODS}

\section{A. Case Study}

To identify and assess the issues surrounding the knowledge, utility, opportunities and challenges that instructors perceive of emerging technologies, a survey was conducted in the Faculty of Land and Food Systems (LFS), at the University of British Columbia (UBC), Vancouver, Canada, as a case study. UBC is a relatively large research university with an enrolment of about 50,000 undergraduate and 10,000 graduate students and over 5,000 teaching instructors and faculty. LFS is a relatively small faculty but is an exemplar of UBC, as its programs range from the applied sciences, with laboratory sections, to the social and economic sciences. Eighty-one full and part-time faculty members are involved in both undergraduate and graduate teaching.

The research methodology provides up close, in-depth, detailed examination of the contextual conditions that frame the adoption of a technology [13], [14]. As suggested in [15], the appropriate use of the case study allows the analyses of persons, events, decisions, periods, projects, policies, institutions, or other systems that are studied often qualitatively and thus illuminates and explains.

Communication was first initiated with the LFS LC, the point of first contact for many instructors' support needs regarding learning technologies. Exploratory discussions informed the identification of key themes, and development of interview questions for face-to-face interviews with participating instructors.

\section{B. Participants and Sampling Strategy}

A stratified random sampling design was employed for selecting interview participants, in order to represent the range of subject areas and categories of instructor positions in LFS. There are 81 faculty members in total in the categories of Professor, Associate Professor, Assistant Professor, Instructor, Lecturer, and Sessional Lecturer. All Professorships and Instructor positions are tenure-track, while all Lecturer and Sessional positions are hired on contract. Faculty members who were not actively involved in teaching (e.g., Adjunct Professors), who were retired, or who were involved directly in this study were precluded from sampling. Therefore, 73 instructors were considered in the sample.

A call for voluntary participation was put out to the instructors and 23 out of 73 eligible faculty members participated in the investigation, with a response rate of $31.5 \%$.

\section{Interview Format}

Interview questions were developed to obtain detailed information from the LFS instructors as to their uses, awareness and concerns on emerging technologies in their teaching practice (see Appendix). Questions were organized according to key variables, including Demographics, Teaching Practices, Learning Technologies, Support \& Professional Development, and Innovativeness. The goal of the interviews was to identify opportunities for how emerging technologies might support teaching and learning from the instructors' perspectives, by collecting information on their needs and expectations for creating an optimal learning environment for students, and for professional development resources.

Semi-structured, face-to-face interviews were conducted and audio recorded with the participant's consent. Participation in this study was voluntary; the results may be biased because the participants may have a particular interest in emerging technologies.

All individual views and opinions provided in the interview remain confidential. Recordings were not transcribed nor coded. Individual audio recordings were summarized, and patterns of responses to the key themes are presented and discussed in this case study. All participants reviewed the report and provided feedback or clarification prior to publication.

\section{RESULTS}

\section{A. Demographics}

The 23 participants bring diverse perspectives based on their areas of interest and academic appointment positions, encompassing the majority of the subject areas taught in LFS. Table I shows the number of participants in different positions.

TABLE I: NUMBER OF PARTICIPANTS IN DIFFERENT TEACHING CATEGORIES IN THE FACULTY OF LAND AND FOOD SYSTEMS

\begin{tabular}{lc}
\hline \hline Position & Number of Interviewees \\
\hline Professor & 3 \\
\hline \hline Associate Professor & 3 \\
\hline \hline Assistant Professor & 4 \\
\hline \hline Senior Lecturer & 2 \\
\hline \hline Instructor & 2 \\
\hline \hline Lecturer & 2 \\
\hline \hline Sessional Lecturer & 7 \\
\hline \hline Total & $\mathbf{2 3}$ \\
\hline \hline
\end{tabular}

Participants' teaching experience at LFS ranged from very limited teaching experience to over 30 years of teaching. Almost half of the participants have been teaching in LFS for over 16 years.

\section{B. Teaching Practices}

\section{1) Types of teaching practices}

Interview participants reported using a variety of teaching practices, ranging from lecturing to problem-based learning and blended learning. It was common that participants used a combination of different approaches. Their teaching practices varied depending on the course content and learning objectives.

The teaching practices that participants mentioned were categorized into: a) Lecturing, b) Problem-based Learning 
(PBL), c) Experiential Learning, and d) Online/Blended Learning. These categories are based upon the interview responses; it is possible that different participants may have used the same term to describe different teaching practices, or may have used different terms to refer to similar practices.

\section{2) "Effective" teaching practices}

The majority of participants suggested that the most effective teaching practice depends on the content and objectives of the course, course level, and class size. Generally, participants reported that "active" teaching practices (such as experiential learning, PBL, and lab work) are more conducive for learning. However, lecturing (a passive learning style), is frequently mentioned as an important and necessary part of teaching. It was common that participants adopted a combination of active and passive teaching practices, and some suggested that this combination makes teaching and learning effective. For example, a course can start with some lecturing, following with PBL, and end with laboratory exercises. Some participants reported adopting a flipped classroom or blended learning style, where students learn and review the basics outside of class time, allowing more time to engage in active learning with their instructor and peers in class.

A few instructors suggested that teaching practice alone does not make learning effective. Other factors reported to influence teaching effectiveness were: interest in the subject matter, rapport with students, humour, praise, and fairness. Class size was deemed important too; participants tend to believe that smaller class sizes are beneficial for effective teaching.

\section{3) Knowledge of teaching practices}

Participants were asked to rate their own knowledge on the teaching practices they had adopted (Fig. 1). Almost $80 \%$ of the instructors reported having between 3 (Fair) and 4 (Good) knowledge of their teaching practices, while very few reported the extremes of the scale. Most of the participants believe that they know how to instruct a class practically, but are largely unaware of educational theories in the academic literature.

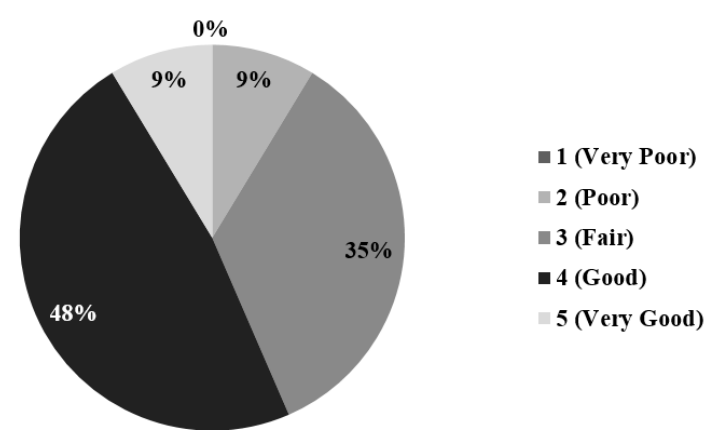

Fig. 1. Participants' rating of their own knowledge of the teaching practices they adopt (Scale 1-5) expressed as \% $(n=23)$. (Due to rounding, percentages do not add up to 100).

Participants provided reasons for their ratings:

1) No formal training or education in the field of teaching or education, and there is an assumption that people with PhDs can teach.

2) No time or little time for participating in teaching workshops.
3) Their primary role is not as an educator, but as a "scientist", and

4) They prioritize their time and resources towards research and publications over developing teaching practices.

These results suggest that appropriate training that fits instructors' needs is necessary, but the question is how and when? Some participants suggested that it is a good idea to invite excellent instructors to share their experiences with the teaching faculty.

Participants' ratings are more varied when it came to the extent that their teaching is informed by best practices or the literature (Fig. 2). Thirty five percent of the participants believe that they are greatly or extremely informed by best practices or literature, while another $35 \%$ indicate that they are slightly or not informed at all. The remainder fall in between or did not respond.

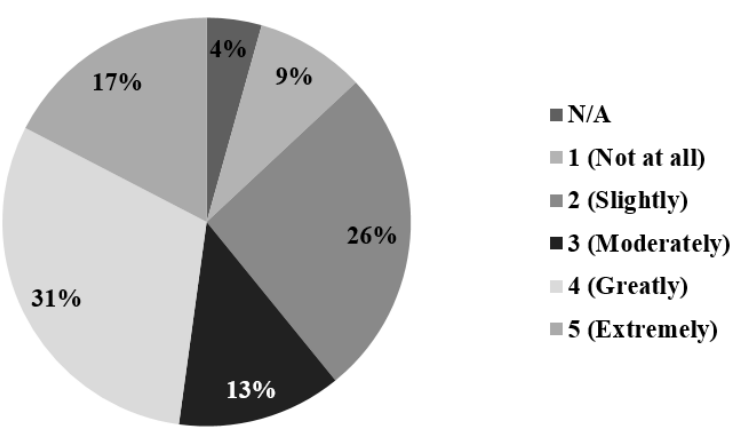

Fig. 2. Participants' rating of how well their teaching is informed by best practices or the literature (Scale 1-5) expressed as \% $(n=23)$.

There is large variation in terms of how well participants feel they are informed. Some participants stated that they make an effort to seek ways to improve their teaching practice, while others do not. The reasons are similar: a) available time, b) incentives, and c) primary role as a "scientist".

Several important points were raised in the interviews about adopting best practices: a) Some practices were not directly related to the subject area that instructors teach in LFS, and therefore, instructors have difficulties replicating those practices in their courses, and b) best practices can be an ongoing process that may take many years to develop, which may affect the response of "new" instructors.

There is an interesting disconnect between the results presented in Figs. 1 and 2. While very few participants reported good knowledge on teaching practices (2 out of 23), over half of the participants felt they are greatly or extremely well-informed by best practices or the literature. This may be due partly to the inclusion of both terms in the same interview question, and the difference in the terms may have been misunderstood. Thus, it is not possible to discern how each of these sources individually informs the participants' teaching practices. To more adequately address this issue will require careful explanation and definition of the context of the working definition of "knowledge of teaching practices".

\section{Learning Technology}

Participants' understanding of learning technologies ranged from physical tools such as the blackboard to highly developed computer-based simulations. Although the definition of learning technology can be contentious, in this 
study we focused on computer-mediated technology that is used to enhance teaching and learning.

Participants reported a variety of computer-mediated technologies used in instruction (Fig. 3). Among these, Connect (a Learning Management System (LMS) that is adopted university-wide), is used by $100 \%$ of the participants. Over half of the participants reported using readily available (e.g., online) videos and animations for teaching. Open access Content Management Systems (CMS) (such as Blogs and Wikis), quiz and feedback tools such as iclickers, and mobile apps were the next most frequently used categories of emerging technologies reported by participants.

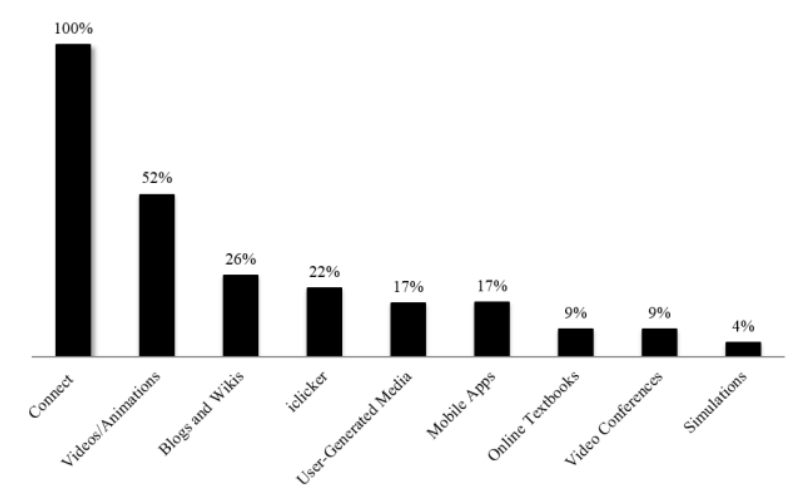

Fig. 3. Different types of computer-mediated technologies reported to be used by participants, as \% of sample $(n=23)$.

Reasons for adopting learning technologies were associated with subject areas, learning objectives, and student needs. Examples of reasons reported in the interviews included the following:

Learning technologies can...

1) Provide flexibility to instructors to edit and update course content,

2) Provide flexibility to different groups of learners, particularly those who need to access education from a distance,

3) Afford better communication and interaction with learners,

4) Support pedagogical practices and learning objectives,

5) Enable students to access resources and learn by themselves out of the classroom, and

6) Enable demonstration and visualization of subject matter and relevant processes.

Several participants suggested that they use emerging technologies in the classroom to connect with a new generation of students, sometimes referred to as digital natives [16], operating on the premise that technology is a fully engrained part of many students' lives, therefore it is logical to include it in their education.

Many participants tended to be cautious about the use of technology in teaching and learning. Some instructors have a strong belief in face-to-face learning, and technology is considered only as a tool to augment this. It is important to consider the learning objectives of a course first, and then determine if a technology can be used to achieve those objectives.

\section{1) "Effective" technology}

Participants identified a range of technologies that they found to be effective, and some that were not effective in their teaching.

a) Connect LMS

In general, participants expressed mixed feelings with Connect. Participants acknowledged the value of having Learning Management Systems such as Connect, and suggested that teaching would be more difficult without them. However, there were more complaints than approval of this particular system; it was generally described as a "cumbersome", "unintuitive", and "inefficient" system that lacks design consideration from instructors' and students' perspectives. Participants also described dissatisfaction due to the fact that a university-wide policy led to the adoption and support of one particular system and may not meet all user needs.

\section{b) iclicker}

Those participants who have adopted and use iclickers, a type of Audience Response System (ARS), suggest that they can be an effective way to attract attention, increase participation, and identify the level of understanding of students in pre- and/or post-assessments. The device affords the opportunity and provides valuable information for contingent teaching, allowing instructors to re-explain concepts or course content in different ways as needs emerge [17].

However, some participants had concerns with iclickers because they require students to purchase an extra device and bring it to every class. Some instructors sensed resistance from students, and therefore decided not to adopt it. Some participants suggested that they were looking for a free, alternative ARS that can be used through students' own mobile devices, so that there is no extra cost for students. Additional considerations with these alternatives are concerns about finding university sources of support.

c) Videos

Over half of the interview participants stated that they used videos in their instruction. In general, videos were used to demonstrate and visualize processes to augment textbooks or lectures. Some participants were familiar with the concept of the "flipped classroom", and suggested that using videos as a pre-class activity was helpful to free up in-class time for more active learning activities, such as discussions and group work [18].

The sources of videos used by participants were mostly from YouTube and other online platforms. Few participants had made their own videos; some suggested that they are attracted to the idea of creating videos themselves, but were concerned with the time investment. A few participants expressed concern that it was difficult to find videos that addressed the desired topic or concept.

Some instructors gave students the option of making their own videos to augment written assignments. These instructors suggested that this can enhance learning, and gave students more options to demonstrate what they learned.

\section{d) Mobile apps and simulations}

Participants reported very positive experiences using mobile apps and simulations. The quality was reported to be generally high, but there are additional costs associated. A few instructors reported that they, in collaboration with professionals, developed mobile apps for field or laboratory 
work. Students could work at specific sites to gather and upload data through the app, or answer questions on the app by observing and analyzing certain subject matter materials such as the soil or plants in the field. Other than mobile apps, web apps were also mentioned. A few participants have developed online apps in collaboration with computer science students. Also, simulations have been developed specifically for laboratory work, allowing students to simulate long-term processes within the timeframe of a particular assignment.

\section{2) Perceptions of available technologies}

Participants were asked to rate the learning technologies that are available to them on a scale from 1 to 5 (1 - Very Poor; 5 - Very Good). The majority of the participants suggested that they were satisfied with current learning technologies (Fig. 4). Sixty five percent of the participants gave a rating equal to, or above 4 (Good), while $22 \%$ gave a rating equal to or below 3 (Acceptable). About $10 \%$ suggested that they could not provide a rating because they do not know enough about what is available. The ratings suggested that the majority of participants were satisfied with the technologies they are using, and the availability of learning technologies at UBC.

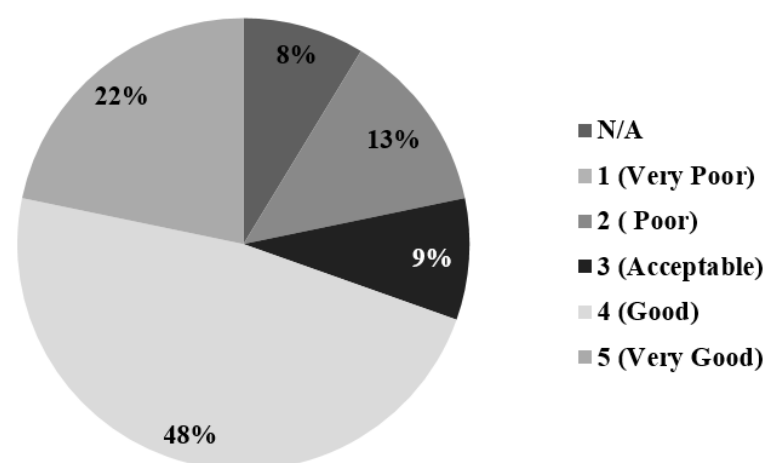

Fig. 4. Participants' ratings (Scale 1-5) of available learning technologies, expressed as \% $(\mathrm{n}=23)$.

In addition to the general ratings, some participants rated specific learning technologies such as Connect and iclicker. Several participants gave a rating of 1 (Very Poor) to Connect, claiming it was not user-friendly. However, iclickers received higher ratings, but participants suggested that there are limits to the utility of these devices.

3) “New" technologies

A recurring theme by participants was the difficulty of knowing what technologies are available, and how to use them appropriately. There was no apparent consensus on which new learning tools or technologies participants would like to try. The idea of "new" depends on what participants had used. Almost all participants referred to something different, ranging from Lightboard technology to Augmented Reality. Many participants mentioned existing UBC-supported technologies such as Camtasia and Wikis. This suggests that it is necessary to determine the specific needs and preferences of each instructor, based on their experience and the subject matter of the courses they teach. The consensus was that when trying new technology, the general goal is greater pedagogical flexibility, especially in conjunction with flexible learning, blended learning, or

\section{flipped classrooms.}

Participants reported two main categories of sources of information about potential learning technologies for their courses. Seventeen out of 23 participants suggested that they rely on personal communication with people who have expertise of emerging technologies at UBC. A few participants, 4 out of 23 , mentioned that they would seek out new technologies on their own accord, by developing partnerships with professionals outside of UBC, or through conversations with students who have experience with technologies.

It was suggested that the LFS LC could provide 1-2 hour introductory workshops highlighting a range of different types of technologies and briefly showcase how they may be used. The main function of such workshops would be to inform instructors of new and emerging technologies as they become available.

\section{4) Challenges with learning technologies}

Participants reported several challenges in using learning technologies for teaching. These challenges may be grouped into three main themes:

1) Technical concerns and complexity of rapidly changing technologies.

2) Available time and resources to devote to learning technologies.

3) How to use technologies effectively and access support.

These themes are broken down into more detail in Fig. 5, which shows the percent of participants reporting specific challenges.

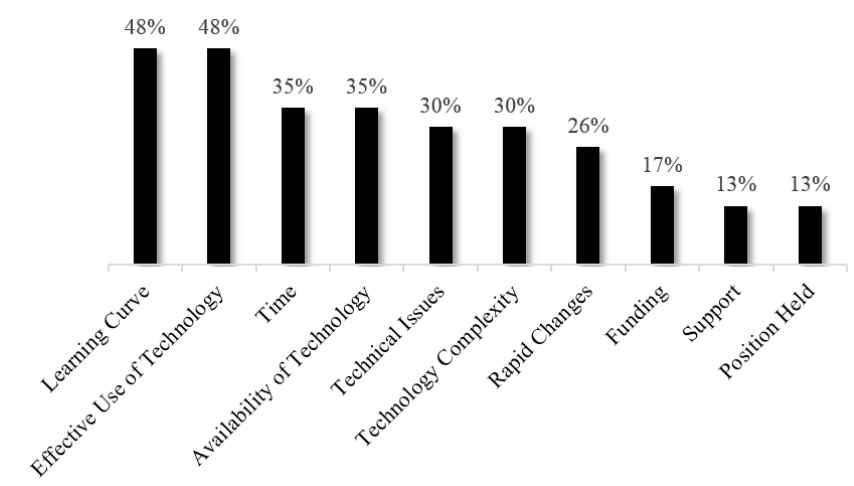

Fig. 5. Specific challenges with learning technologies reported by participants as a $\%(n=23)$

\section{a) Technical concerns and complexity of rapidly} changing technologies

Almost half of the participants emphasized that there is a steep learning curve for effectively using each new technology in the classroom (physical or virtual) to achieve learning objectives. The learning curve is understood as the time and effort spent on learning how to use a specific technology, and developing the competence to use it effectively, creatively, and in a pedagogically sound manner. Thirty-five percent of the participants explicitly stated that they have no time or very limited time to spend on learning a new technology. In addition, 35\% suggest that the availability, or knowing the availability of, a learning technology is challenging.

Technical issues such as network connection and hardware problems were also frequently mentioned. Over $30 \%$ of the 
instructors expressed an anxiety of facing technical issues in front of the class. The complexity of technology can be a potential barrier to use. Over $30 \%$ of the instructors stated that the design of learning technology is often very complicated. Participants tended to associate the complexity of technology with their experiences in using Connect. There was also reported concern that while instructors are investing time and money into a current version of some technology, a new version or some improved alternative is released, which requires extra time and resources to adapt to the new technology.

\section{b) Available time and resources to devote to learning technologies}

Institutional and/or personal challenges were also raised in the interviews. A common concern was the unclear expectations of instructors' responsibilities associated with their appointment within LFS. There was repeated comment that those who hold tenured or tenure-track positions are judged mainly by their scientific and scholarly achievements, in particular by publications (rather than teaching or innovations in teaching). Furthermore, the compensation for establishing a new course is not adequate for the time and effort invested.

The issue of identity was a recurring theme that emerged from the interviews. Some participants said they were struggling with switching between multiple identities such as scientist, educator, and technician. Many participants, regardless of their position in the faculty, would self-identify as scientists first, and then as instructors. Many participants suggest that they are learning to be an instructor in practice, since they are typically very well trained in their discipline. Some participants strongly resist the idea of being a "technical person". They prefer not to be spending their time on learning new technologies or solving technical issues. But it is generally acknowledged that instructors must spend some of their time on the technical aspects of these emerging learning technologies.

A lack of available funding was considered to be a major concern when using learning technologies. Many participants suggested that, regardless of their position in the faculty, they do not have or have only minimal access to funds for teaching. Monetary concerns are related to both process and cost-benefit. There are questions such as where the money is from, who is applying for it, and how much benefit the cost would bring. Applying for a teaching grant from UBC is one option, but this takes additional time to prepare a proposal, and only a few obtain funding. Although there is support from the LC, instructors suggest there are difficulties receiving support in a timely manner.

Many of these challenges are interrelated. Central to the challenges is the time that needs to be spent using technology effectively to support learning objectives, but time is also associated with many other challenges. The academic position instructors hold would structurally prioritize their tasks, and there was uncertainty on whether learning and adopting a new technology contributes to their academic advancement. A tenure-track research professor is less likely to prioritize teaching-related activities than those who are hired for teaching. However, a sessional lecturer may have another part-time or full-time job within in or outside of
UBC.

In addition, the complexity of a technology influences the time that instructors need to spend to become effective. Available support for fixing technical issues also has an impact on the time needed. The longer instructors must wait for support, the more likely instructors will spend more time to troubleshoot by themselves, or abandon the technology.

c) How to use technologies effectively and access support

Support for instructors is crucial. Having professionals to support technical needs was a common theme. In addition to technical aspects, support can be understood as training opportunities provided by the LC or the CTLT. The consensus was that the more appropriate training instructors receive, the more likely they would be able to use technology effectively.

There were suggestions that "Learning Centres" that focused on a department or faculty were much better than having only a centralized teaching support facility. However, it was suggested that the LFS LC should take a more proactive role in communicating what emerging technologies are available and what can be adopted, since many people are not aware of what is available. In addition, changes in technology may bring new technical issues such as compatibility of different platforms, or workload issues since instructors need to learn how to use the new technology. Participants suggested further that it is important to provide initial support when adopting or transiting to new technology or platform. One participant pointed out that there was no support from the LC at the beginning of the transition to the Connect LMS.

On the other hand, a few participants suggest that UBC encourages innovation and they did not experience any constraints. But there are concerns with regard to the institutional enthusiasm towards and recognition of adopting learning technology. A few participants described the enthusiasm as an "unreflective promotion of technology", and suggested that there should be more consideration learning outcomes than technology.

\section{Support and Professional Development}

Fifteen out of 23 participants $(65 \%)$ reported that they were well supported by LFS, while 4 participants $(17 \%)$ suggested that they did not feel supported at all. In general, participants said that their colleagues were very supportive, and that the LC has been a great source of support. Compared to the centralized CTLT, a few participants emphasized the value of having the LC housed within LFS.

During the interviews, some participants requested more support from LFS leadership, including:

- Greater recognition of teaching (formal or informal),

- Providing more instructional, technological, and budgetary support for course design or re-design,

- Providing informational workshops introducing learning technologies to instructors,

- Improving response time (not necessarily time to resolve an issue) from the LC,

- Working towards improving the Connect LMS. The LC should act as an advocate and establish communication channels for instructors to talk about the challenges and 
improvements needed, and

- Provide support and recognition for sessional lecturers, such as providing resources or workshops specific for sessional lecturers outside of regular hours. Considering the large number of sessional lecturers, this may be a serious emergent issue for more faculty members hired as sessional lecturers in the future.

\section{1) Support resources}

A number of different organizations were identified by the participants as resources to support their teaching (Table II). Within LFS, peer evaluation was considered as a valuable internal program that supports teaching. The results suggest that the majority of participants are aware the CTLT or LC as a resource for teaching support or professional development.

TABLE II: UBC TEACHING SUPPORT ORGANIZATIONS, IDENTIFIED BY

\begin{tabular}{lc}
\multicolumn{1}{c}{ PARTICIPANTS AS A \% (N=23) [19] } \\
\hline $\begin{array}{l}\text { Teaching Support } \\
\text { Organization }\end{array}$ & $\begin{array}{l}\text { Percent of Participants } \\
\text { Reporting }\end{array}$ \\
\hline $\begin{array}{l}\text { Centre for Teaching, Learning } \\
\text { and Technology (CTLT) }\end{array}$ & $87 \%$ \\
\hline \hline LFS Learning Centre (LC) & $87 \%$ \\
\hline Communities of Practice & $9 \%$ \\
\hline \hline Peer Evaluation & $9 \%$ \\
\hline \hline Library & $9 \%$ \\
\hline \hline Acentre for Teaching and & $9 \%$ \\
\hline \hline Continuing Education & $4 \%$ \\
\hline \hline
\end{tabular}

\section{2) Professional development}

A large number of participants indicated that they would like to access professional development workshops and seminars. Specific workshop or seminar topics were suggested:

- Introduction of emerging technologies that are available in LFS for instructors.

- Recommended specific teaching practices for subject matter taught in LFS.

- Enhancing lecture-based teaching; for example, how to better engage with students.

- Brown bag lunch sessions regarding practical and technical topics.

- New and innovative technologies such as mobile or web applications.

While participants listed the workshops they would like to access, some expressed concern that they may not have the time to attend or would not prioritize attending workshops. More online resources may be desirable, particularly short videos, but participants suggested that online resources are not effective when a new technology or system is introduced.

About half of the participants suggested that they could not think of any resources they need to access, either because they are satisfied with what is available now, or they simply could not list those resources.

\section{E. Diffusion of Innovations}

Using categories of innovativeness, as modified from Rogers' Diffusion of Innovations theory [11], participants were asked to self-identify (Fig. 6). These results help to gauge how innovations in teaching and learning are shared amongst instructors in LFS. (For a description of each of the categories, refer to p. 23 in the Appendix.) As Fig. 6 shows, the majority of the participants (19 out of 23) fall into the first three categories.

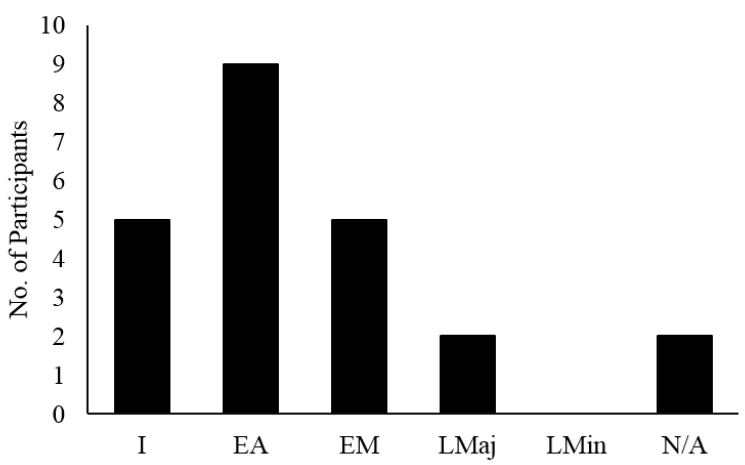

Fig. 6. Instructors' self-identified categories of "innovativeness", reported as number of participants $(\mathrm{n}=23)$. I=Innovator; $\mathrm{EA}=$ Early Adopter; EM=Early Majority; LMaj=Late Majority; LMin=Late Minority.

It is possible that those who were willing to participate in the interviews were more receptive to emerging technologies, and thus would appear on the innovator side of the spectrum. Although there might be a concern about the distribution of the voluntary responses from the professorial categories and the instructor/lecturer categories, the synthesis of the responses revealed similar results.

\section{DISCUSSION}

The study revealed that instructors in LFS are aware of and embrace the adoption of emerging technologies to enhance their teaching effectiveness. It was recognized that education in emerging technologies is needed for instructors to become more fluent in these tools, but the type of training or assistance desired was either inconsistent or not clearly identified. As noted in [20], how to transition instructors out of the beginner or novice stage to become more familiar with emerging technologies in the classroom remains an open question, and a challenge.

Participants identified positive opportunities to communicate and share experiences with fellow instructors, but it is recommended that emerging technologies training is integrated with instructional skills training in general. The research on integrating technology into instructor education and professional development identifies three clear threads: the importance of intrinsic factors such as attitude while learning technology, the necessity of engaging in meaningful technology experiences, and the importance of learning technology in collaborative and supportive settings [20]. Instructors who are recipients of training or assistance have reduced anxiety about using emerging technologies, thus improving their confidence and attitude [21]. With greater literacy of emerging technologies, opportunities arise for instructors to become more creative in their application in the classroom. This growth can drive the instructor's (perceived) position on Rogers' scale of innovativeness towards early adopter or innovator [11].

If a goal of a university is to educate, that is, to develop and transfer knowledge and enhance the inner potential of individuals [22], then universities must ensure that 
instructors are provided with the capabilities, tools and opportunities to educate their students at a high quality level. As emerging technologies, and thus modes of course/curriculum delivery, are evolving rapidly, instructors must not be left behind in their ability to utilize and apply these tools to support the dissemination of knowledge. Conversely, there is a need to consult/communicate with instructors before the development and adoption of learning technologies, to ensure that they are used effectively in teaching and learning; this was indicated by participant dissatisfaction with the utility of the Connect LMS (even though it was widely used).

Although it was generally felt that excellence in teaching was an important goal of instructors in LFS, concerns were expressed that teaching of courses is perceived to be of lesser importance than research productivity. Participants also expressed that the time and resources required to keep informed and become proficient in the adoption of a technology were limiting factors. Further research into effective instructor training and support is recommended at some institutional level (the LFS LC and CTLT), to streamline opportunities for instructor career growth. A few participants emphasized that the system for teaching evaluation and recognizing merit could be improved by incorporating more formal and/or informal recognition of adoption of learning technologies.

Several questions and challenges were identified, such as: What should training programs or initiatives look like? Should these opportunities be offered on a voluntary basis? This may only help those instructors who are "early adopters", who would likely take the initiative regardless. Should this training be offered in conjunction with career advancement opportunities such as promotions and/or salary raises? This might provide incentives for those instructors who are "late adopters". What types of instructor education or training models are preferred for faculty members whose time is already stretched between research and teaching commitments? More of a one-on-one consulting model where they get a review of what they're doing well and advice on where they can improve? If this training is recognized as professional development for instructors, could it be integrated with employee reviews and evaluations and provide incentives for instructors that way? How can the institutional leadership encourage innovators to educate their colleagues on emerging technologies, which [2] have shown can be an effective complement to formal training? Further research is needed to elucidate these concerns.

We propose a conceptual framework adapted from [23], to guide various actors within this case study to understand better their interrelationships and to identify needs and opportunities in order to enhance teaching practices in LFS (Fig. 7).

The key actors in the conceptual framework are the Instructor as the Adopter of a learning technology, the LFS Learning Centre or CTLT as the Linker, which shares technical expertise with the Adopter, and is guided by university policies on teaching and learning, and finally, UBC Policymakers, connected to other actors through the CTLT office, act as the Institutional Leader. The Institutional Leader could also be represented by the Dean at the Faculty level.

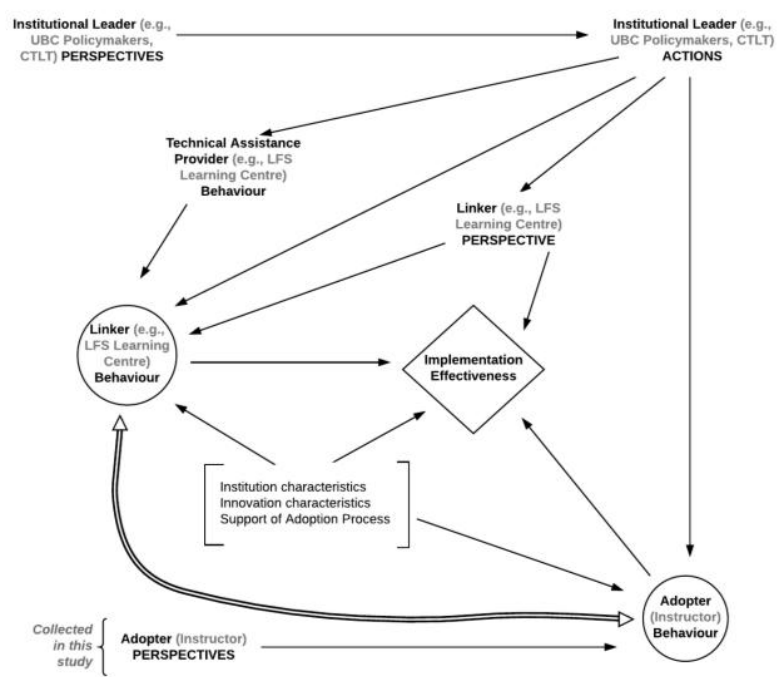

Fig. 7. Conceptual framework diagram for dissemination of education innovations, identifying specific actors in this case study (green). Adapted from [23]

The CTLT and LFS Learning Centre (Linkers) are established service centres, both with mandates to support instructors with teaching and learning technologies; however, they tend to operate in a reactive manner (e.g., instructor comes with a problem to be fixed). With a clearer path of communication, these centres and the instructors can work more proactively together to host workshops and training opportunities (supported by the Institutional Leader, for example, professional development recognition), on what emerging technologies are available and suitable for individual teaching needs.

There is a need for commitment from the Institutional Leadership to establish communication channels and facilitate dialogue between Adopters and Linkers. The Linker should regularly consult with Adopters to determine their training needs but also to solicit feedback on new or proposed technologies, prior to university-wide adoption (as indicated by the two-way arrow in Fig. 7). This would be particularly beneficial with "Innovators" and "Early Adopters" (see Fig. 6 ), who can share their insights and experience with emerging technologies to the Linker, who can then communicate both to other Adopters and to Institutional Leaders.

Implementation effectiveness of emerging technologies (diamond in Fig. 7) to support teaching and learning relies on Adopter behaviour. Institution characteristics, namely the Institutional Leadership and its policies, and the Linker, or point of contact for Adopters, and Innovation characteristics influence Adopter behaviour. There is great opportunity for "Innovators" to share their experience with other Adopters, particularly to Sessional Lecturers, who may have less incentive to apply emerging technologies in a course. Innovators can also inform the Linker and even the Institutional Leader.

\section{CONCLUSION}

The majority of participants, regardless of academic appointment or years of service, were enthusiastic about 
teaching and improving their teaching practices. While many stated that they were not informed by the academic literature on pedagogy, most participants felt their teaching was guided by best practices, notably peer evaluation. All participants utilized some form of learning technology to support their teaching practice, but there was a range in the level of perceived availability and adoption.

The enhancement of the teaching and learning environment within LFS in relation to the breadth of, and at times unique needs for, particular learning outcomes presents challenges to both instructor performance and supporting resources. LFS instructors faced several challenges when considering whether to adopt a learning technology, namely: 1) Technical concerns and the complexity of rapidly changing technologies, 2) Available time and resources to devote to learning technologies, and 3) How to use technologies effectively and access support.

There was uncertainty about how an investment in learning technologies in teaching related to an individual's appointment, in terms of career recognition and professional development. In addition, the mechanism is unclear on how learning technologies are expected to be implemented in the context of the university institution (i.e., how university policy translates to instructor behaviour and adoption of new technologies). There is a need and opportunity for more streamlined communication between the important actors, including the Adopters and Institutional Leaders. The LFS Learning Centre was identified as playing an important mediating or linker role. There is great opportunity for this actor to play a greater consultative role in reaching out to instructors on what their learning technology needs and wants are, to better tailor their support, since one size does not fit all.

Participants in this study largely self-identified as Innovators and Early adopters on the scale of innovativeness. These people are in a pertinent position to facilitate the diffusion of innovations in teaching and learning to their colleagues, who may appear on the late adopter side of the spectrum. Innovators are encouraged to continue with their practices and to share their experiences using emerging technologies in their teaching with their colleagues. It is valuable for instructors to be aware of each other's practices, and word-of-mouth and personal recommendations were found to be important channels for communication and diffusion of innovations in LFS.

Further research is needed to better understand what the emerging technologies are that instructors find effective in helping students achieve their learning objectives. While the Faculty of Land and Food Systems is an exemplar because of its range of programs, wider-scale sampling is required across multiple faculties (and universities) to obtain more representative results of the higher education system. To complement this research, future study is needed on a key actor that is missing from the conceptual framework: the student perspective on emerging technologies in higher education. While instructors need support to proficiently use a learning technology in a course, it is key that students also find utility in the adopted learning technology, and have an avenue through which to provide feedback. Continuing both formal and informal communications is key to build and maintain a top-quality teaching and learning environment in the Faculty of Land and Food Systems and in higher education overall.

\section{APPENDIX}

\section{A. Interview Questions}

\section{1) Demographics}

1) How many years have you been teaching (in LFS)?

2) What (level of) courses have you taught?

Learning Technology

3) What technologies do you use most frequently to support teaching and learning? (Choose all that apply):

- LMS \& CMS

- Blog \& Wikis

- Media \& Media Production

- Social Media

- Quiz \& Feedback Tools (Scantron, iclicker, IPeer)

- Game \& Simulation

- Others

4) Why did you select these technologies? What prompted your interest to use them?

5) Which one(s) do you find most effective in your teaching? Think in the context of a specific course. (Choose all that apply):

- LMS \& CMS

- Blog \& Wikis

- Media \& Media Production

- Social Media

- Quiz \& Feedback Tools (Scantron, iclicker, IPeer)

- Game \& Simulation

- Others What made it/them effective?

6) What are the challenges in using technology for teaching in general?

7) How would you rate currently available learning technologies?

1 - Very Poor 2-Poor 3-Acceptable 4-Good

5 - Very Good

(Please describe your rating)

8) How do you find out about new technology that is appropriate for your teaching? What are the sources?

9) What are the new tools or technologies you would like to try?

10) What are the institutional and/or personal constraints in adopting new technologies?

2) Learning spaces

11) Think of the place where you teach the most (or in a particular course). How does this learning space support your teaching practices? What are the challenges?

12) How would you rate current learning spaces in LFS in general?

1 - Very Poor 2-Poor 3-Acceptable 4-Good

5 - Very Good

(Please describe your rating)

13) What are the learning spaces you would like to use on campus? Are there any problems when accessing these spaces?

14) What improvements would you like to see in the 
physical spaces in LFS? How could the spaces be re-designed to support you to try out new things?

15) What would an optimal learning environment look like to you for that particular course?

\section{3) Teaching practices}

A wide range of teaching practices are used in the faculty, for example, small group work, lectures and labs, problem-based learning, blended and flipped classrooms, field courses, directed studies, online courses...

16) What teaching practices have you used for your course?

17) Which have you found to be most effective and why?

18) How would you rate your knowledge on pedagogy/teaching practices?

1 - Very Poor 2 - Poor 3-Fair 4-Good 5 -

Very Good

(Please describe your rating)

19) To what extent are you informed by literature or best practices for teaching and learning?

1 - Not at all 2-Slightly 3-Moderately

$4-$

Greatly

(Please describe your rating)

\section{4) Support and professional development}

20) What facilities or organizations that support teaching are you aware of on campus? Which of these have you utilized most to support your teaching?

21) How often do you interact with the Learning Centre in LFS?

1 - Never

2 - Sometimes (less than 5 times a year)

3 - Often (one or two times a month)

4 - Very frequently (once a week or more)

(Please describe your rating)

22) To what extent do you feel supported by the LFS faculty? Why? What can the LFS Faculty or the Learning Centre do to better support you?

23) What resources would you like to access for professional development?

24) What are your preferred ways of receiving information?

5) Innovativeness

25) How would you categorize yourself in terms of innovativeness [11]?

- Innovator: venturesome, daring, risky, eager to try new ideas, able to deal with high degree of uncertainty, willing to accept setbacks, may not be respected by other members, launch new ideas in the social system by importing the innovation from outside of the system's boundaries.

- Early Adopter: respected by his or her peers, embodiment of successful and discrete use of new ideas, continue to earn this esteem of colleagues and to maintain a central position in the communication structure of the system, decrease uncertainty about a new idea by adopting it, convey a subjective evaluation of the innovation to near-peers.

- Early Majority: deliberate for some time before completely adopting a new idea, "be not the first by which the new is tried, nor the last to lay the old aside", follow with deliberate willingness in adopting innovations, but seldom lead.
- Late Majority: skeptical and cautious to new ideas, do not adopt until most others in their social system have done so, may be persuaded of the utility of new ideas and the pressure of peers.

- Late Minority: resistant, tend to be frankly suspicious of innovations and change agents, last in a social system to adopt an innovation.

\section{6) Closing}

Who might have a different perspective than you? Is there anything I should have asked but I didn't?

\section{ACKNOWLEDGMENT}

The authors would like to thank all the interview participants for their contributions to this study.

\section{REFERENCES}

[1] L. S. Bassendowski and P. Petrucka, "Are 20th-century methods of teaching applicable in the 21st century?" British Journal of Educational Technology, vol. 44, no. 4, pp. 665-667, 2013.

[2] D. Ng'ambi and V. Bozalek, "Leveraging informal leadership in higher education institutions: A case of diffusion of emerging technologies in a southern context," British Journal of Educational Technology, vol. 44, no. 6, pp. 940-950, 2013.

[3] UBC Flexible Learning. (2016). Flexible learning. [Online]. Available: http://flexible.learning.ubc.ca

[4] J. Hill, "Flexible learning environments: Leveraging the affordances of flexible delivery and flexible learning," Innovative Higher Education, vol. 31, p. 9016, 2016.

[5] S. Ahalt and K. Fecho, "Ten emerging technologies for higher education," RENCI White Paper Series, University of North Carolina at Chapel Hill, vol. 3, no. 1, 2015.

[6] D. R. Garrison and H. Kanuka, "Blended learning: Uncovering its transformative potential in higher education," Internet and Higher Education, vol. 7, pp. 95-105, 2004.

[7] C. C. Lewis, C. E. Fretwell, J. Ryan, and J. B. Parham, "Faculty use of established and emerging technologies in higher education: A unified theory of acceptance and use of technology perspective," International Journal of Higher Education, vol. 2, no. 2, pp. 22-34, 2013.

[8] N. Dabbagh and A. Kitsantas, "Personal Learning Environments, social media, and self-regulated learning: A natural formula for connecting formal and informal learning," Internet and Higher Education, vol. 15 , pp. 3-8, 2012.

[9] E. Dahlstrom, and J. Bichsel, "ECAR study of undergraduate students and information technology," EDUCAUSE Center for Analysis and Research Report, October 2014.

[10] J. Yarbro, K. M. Arfstrom, K. McKnight, and P. McKnight, "Extension of a review of flipped learning," Flipped Learning Network-PEARSON-George Mason University Publication, 2014.

[11] E. M. Rogers, Diffusion of Innovations, 5th ed. New York, U.S.A.: Free Press, 2003, ch. 7, pp. 282-285.

[12] UBC Faculty of Land and Food Systems. (2016). Land and Food Systems Learning Centre. [Online]. Available: http://lc.landfood.ubc.ca/about/

[13] B. MacDonald and R. Walker, "Case Study and the social philosophy of educational research," Cambridge Journal of Education, vol. 5, pp. 2-11, 1975.

[14] R. Yin, Case Study Research: Design and Methods, 5th ed. Thousand Oaks, U.S.A.: Sage, 2014.

[15] G. Thomas, How to do Your Case Study: A Guide for Students and Researchers. Thousand Oaks, U.S.A.: Sage, 2011.

[16] E. J. Helsper, and R. Eynon, "Digital natives: Where is the evidence?" British Educational Research Journal, vol. 36, no. 3, pp. 503-520, 2010.

[17] J. Pol, M. Volman, and J. Beishuizen, "Patterns of contingent teaching in teacher-student interaction," Learning and Instruction, vol. 21, pp. 46-57, 2011.

[18] J. W. Baker, "The "classroom flip": Using web course management tools to become a guide by the side," presented at the 11th International Conference on College Teaching and Learning, Jacksonville, FL, 2000.

[19] UBC. (2016). Strategic Priorities - Student Learning. [Online]. Available:

http://www.ubc.ca/strategic-priorities/student-learning/index.html 
[20] D. L. Bruce and M. M. Chiu, "Composing with new technology: Teacher reflections on learning digital video," Journal of Teacher Education, vol. 66, no. 3, pp. 272-287, 2015.

[21] D. D. Agyei, and J. M. Voogt, "Exploring the potential of the will, skill, tool model in Ghana: Predicting prospective and practicing teachers' use of technology," Computers \& Education, vol. 56, pp. 91-100, 2011.

[22] K. P. Mohanan. (2005). University education for career advancement: The profile of a successful candidate. Centre for Development of Teaching and Learning, National University of Singapore. [Online]. Available: http://www.cdtl.nus.edu.sg/publications/career/goals.htm

[23] Network of Innovative Schools, Inc., "Conceptual framework: A study of dissemination efforts supporting school improvement, Andover, MA," in Qualitative Data Analysis - An Expanded Sourcebook, $2^{\text {nd }}$ ed. London, UK: Sage, 1979.

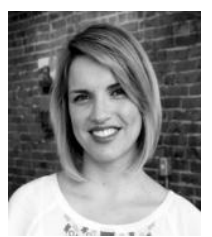

Julie E. Wilson is from Vancouver, British Columbia, Canada. Her education was based at the University of British Columbia (UBC), Vancouver, Canada, where she obtained her BSc in environmental science (2007) and the MSc in resource management and environmental studies (2010).

She is a lecturer in professional communications, land and water systems and urban watershed management in the Faculty of Land and Food Systems, UBC, Vancouver, Canada. She is the Academic Coordinator of the professional Master of Land and Water Systems program at UBC, where she advises on students' major projects. Previously, she was the Science Communication coordinator for the Canadian Natural Sciences and Engineering Research Council graduate student training program, TerreWEB, at UBC, where she researched and developed resources for using emerging technologies in learning and communication of scientific research She has been the co-recipient of UBC's Teaching and Learning Enhancement Fund for the development of innovative, online and open-access educational resources in soil science for secondary and post-secondary students. She has worked as a research assistant on watershed assessment and management projects at the University of Saskatchewan, Saskatoon, Canada and UBC.

Ms. Wilson is a professional agrologist in the province of British Columbia, Canada. She has recently published in the journal of Natural Sciences Education, Integrated Environmental Assessment and Management, Journal of Open Forestry, and the Journal of Agriculture, Food Systems and Community Development. She is a member of the Pacific Regional Society of Soil Science and the Canadian Society of Soil Science, and is a Canadian Water Network Young Professional.

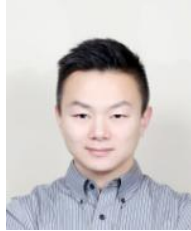

Junsong Zhang received his BA in psychology education (2013) from South China Normal University, Guangzhou, China, and his MEd from the Faculty of Education (2015) at the University of British Columbia, Vancouver, Canada. He is now working for the Insurance Corporation of British Columbia, Vancouver, Canada, as a learning technology analyst. During his study at UBC, he specialized in learning design and educational technology and was involved in different research projects with faculties and students at UBC and SFU.

Mr. Zhang is co-author of "An entertaining game-like learning environment in virtual world for education" in S. D'Agustina (Ed.), Creating Teaching Immediacy in Online Learning Environments, IGI Global (2016). He is a member of the Virtual Commons for Education Research at UBC, and the Human Resources Management Association.

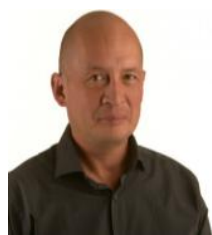

Cyprien Lomas was born in Vancouver, British Columbia, Canada. He has a Ph.D. in cellular immunology (2000) and a B.Sc. in microbiology and immunology (1987) from the University of British Columbia, Vancouver, Canada. Cyprien has spent the last sixteen years working in field of learning, teaching and communication of science using technology.
He works as the director of the Learning Centre and Assistant Dean, Learning Technology in the Faculty of Land and Food System at the University of British Columbia in Vancouver, BC, Canada. He previously worked in the Faculty of Science in the Science Centre for Teaching and Learning. Previous publications include Design of the Learning Space: Learning and Design Principles (Boulder, CO, 2005, Educause) and Collaboration Tools (Boulder, CO, 2008, Educause) Current research interests include identifying strategies to help students effectively communicate using new and existing technologies and designing and assessing effective learning environments for formal, informal and in the field learning environments. Previous interests have included identifying infrastructure needed to support faculty, staff and student development and assessing the fit of emerging technologies for learning and teaching strategies

Dr. Lomas is an Apple Distinguished Educator and has just completed serving for ten years on the Educause Learning Initiative ' 7 Things You Should Know' advisory committee. Dr. Lomas originated the series in 2005. Previous advisory work included serving on the Horizon Report advisory board from $2005-2014$.

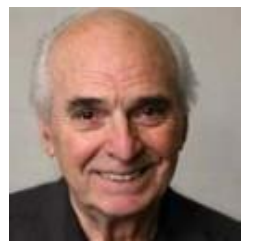

Les M. Lavkulich is from Lethbridge, Alberta, Canada. He completed his BSc with distinction in earth science (1961) and the MSc in soil science (1963) at the University of Alberta, Edmonton, Canada. He completed his PhD at Cornell University, New York, USA in Soil Genesis, Chemistry (1966).

$\mathrm{He}$ serves as the director of the professional master's program in land and water systems and the global resources system program in the Faculty of Land and Food Systems, the University of British Columbia (UBC), Vancouver, Canada. He is a Professor Emeritus in Soil Science and his teaching responsibilities included introductory soil science, soil chemistry and mineralogy, land classification and pedology. His academic focus is the mentoring of students and to conduct research to promote the application of natural science information to facilitate informed debate on responsible environmental stewardship. He was the Head of Soil Science and founding Director of the interdisciplinary Resource Management and Environmental Studies graduate program and the Institute for Resources, Environment and Sustainability at UBC.

Dr. Lavkulich has authored over 250 refereed publications, several invitational chapters in textbooks, the Canadian Encyclopedia, and was expert witness to the Senate of Canada, the Hon. H.O. Sparrow Commission. He is the past President and Fellow of the Canadian Soil Science Society and a Fellow of the British Columbia Science Council.

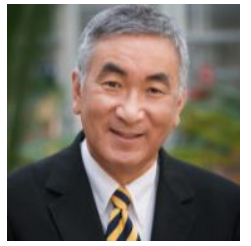

Rickey Y. Yada is from Vancouver, British Columbia, Canada. His education was based at the University of British Columbia (UBC), Vancouver, Canada, where he obtained his BSc in agriculture (1977), the MSc in food science (1980) and the PhD in food science (1984).

He has been the dean of the Faculty of Land and Food Systems, and Professor of Food Science at UBC in Vancouver, Canada since 2014. Prior to joining UBC, he was at the University of Guelph, Ontario, Canada, in a number of leadership roles, including Professor in the Department of Food Science, Chair of the Department of Food Science, Assistant Vice President Research, a Canada Research Chair in Food Protein Structure, and a Founding Member of the Food Institute. He was also the Vice Chair of the Canadian Institutes of Health Research, Institute of Nutrition, Metabolism and Diabetes.

Dr. Yada is a member of the Board of Trustees International Life Science Institute - North America, the North American Editor for Trends in Food Science and Technology, and on editorial boards for several journals. He is also the author of over 200 refereed journal publications and several book chapters. Dr. Yada is a Past President and Fellow of the Canadian Institute of Food Science and Technology, Past President and Fellow of the International Academy of International Union of Food Science and Technology as well as a Fellow of the Institute of Food Technologists. 